\title{
Reduction in mortality from sudden infant death syndrome in New Zealand: 1986-92
}

\author{
E A Mitchell, J M Brunt, C Everard
}

\begin{abstract}
Mortality from sudden infant death syndrome (SIDS, or cot death) in New Zealand has been high by international standards (4/1000 live births). Within New Zealand the rate is higher in Maori than in non-Maori (predominantly European infants) and higher in South Island than in North Island. The National Cot Death Prevention Programme aims to reduce the prevalence of four modifiable risk factors for SIDS, namely infants sleeping prone, maternal smoking, lack of breast feeding, and infants sharing a bed with another person. The aim of this study is to describe the total postneonatal and total SIDS mortality in New Zealand from 1986 to 1992 . Official publications from 1986 to 1990 and preliminary death notifications for 1991 and 1992 were examined.

Deaths from all causes in the postneonatal age group (28 days to 1 year) and the total number of deaths from SIDS irrespective of age decreased markedly in 1990 and has continued to decrease. This decrease occurred particularly in nonMaori groups, in South Island, and in the winter months.
\end{abstract}

The proportion of infants sleeping in a prone position has decreased from $43 \%$ to less than $5 \%$. This suggests that the prone position is causally related to SIDS. The mechanism appears to be related directly or indirectly to environmental temperature.

(Arch Dis Child 1994; 70: 291-294)

Department of

Paediatrics, University

of Auckland,

Auckland, New

Zealand

E A Mitchell

New Zealand Health Information Service, Ministry of Health

J M Brunt

Department of Paediatrics, University of Auckland,

Auckland, New

Zealand

C Everard

Correspondence to:

Dr E A Mitchell,

Department of Paediatrics,

School of Medicine,

University of Auckland,

Private Bag 92019 ,

Auckland, New Zealand.

No reprints available.

Accepted 6 January 1994
Postneonatal mortality (in the age group 28 days to 1 year) in New Zealand has been high by international standards (6/1000 live births). This high rate is predominantly due to the high mortality from sudden infant death syndrome (SIDS, or cot death), a rate higher than that reported from any other country. There is a marked increase in mortality from north to south in New Zealand. New Zealand has two main islands (North and South Islands) and spans $35^{\circ} \mathrm{S}$ to $47^{\circ} \mathrm{S}$ (about $1400 \mathrm{~km}$ or 900 miles); it is subtropical in the north of North Island and coolly temperate in the south. This suggests a relationship between SIDS and environmental temperature. In addition, there is a marked ethnic variation in mortality from SIDS, with the rate in Maori groups twice that of non-Maori groups, who are predominantly European. These factors stimulated the development of a three year (1 November 1987-31 October 1990) nationwide case- control study to identify the risk factors for SIDS. The results from the first year of the study suggested that prone sleeping position, maternal smoking, and lack of breast feeding increased the risk of SIDS, and that if these risk factors were totally avoided then mortality from SIDS in New Zealand might decrease by $78 \% .^{1}$ Other studies had also identified these risk factors. ${ }^{2-6}$ More recently families have been advised not to sleep with their infant. ${ }^{7}$

New Zealand was the first country to launch a formal cot death prevention programme. The planning and implementation of this programme has been described in detail previously.$^{8}$ The prevalence of the prone sleeping position was seen to decrease before the launch of the programme, however, and this was associated with a reduction in mortality from SIDS. ${ }^{9}$ We were also able to show that the prevalence of other known risk factors did not change during this period. ${ }^{9}$

The aim of this paper is to describe the changes in total postneonatal and SIDS mortality in New Zealand from 1986 to 1992.

\section{Methods}

The following information was extracted from the publications of Fetal and Infant Deaths (Department of Health) for 1986, 1987, and 1988-90: (a) postneonatal deaths (live born infants dying between the ages of 28 days and 1 year) - number of deaths by region and ethnicity; (b) live births - number of live births by region and ethnicity; and (c) SIDS - total number of deaths in childhood which were attributed to SIDS, by ethnicity and month of death. This includes cases outside the postneonatal age group and also cases where, in addition to SIDS, another disorder was reported to be present at the time of death (for example, pneumonitis). World Health Organisation rules for the selection of underlying cause of death require that specific diseases and disorders are given precedence over non-specific causes such as SIDS. This means that where SIDS is reported together with another disorder the rules require that the other disorder is selected and classified as the cause of death. To capture information about all of the deaths reported to be due to SIDS, the New Zealand Health Information Service uses a flag (' $Y$ ' indicator) to identify all the SIDS records, including those classified to ICD code 798.0 and those classified to other disorders. The cases of SIDS classified to 'other' disorders are mainly incidental findings at necropsy, such as respiratory pathologies considered by the reporting pathologist to be 
Table 1 National total postneonatal deaths: numbers (rates per 1000 live births) from all causes by ethnicity, 1986-92

\begin{tabular}{llll}
\hline Year & Maori & Non-Maor & Total \\
\hline 1986 & $63(9 \cdot 7)$ & $266(5 \cdot 7)$ & $329(6 \cdot 2)$ \\
1987 & $77(11 \cdot 0)$ & $247(5 \cdot 1)$ & $324(5 \cdot 9)$ \\
1988 & $74(10 \cdot 9)$ & $276(5 \cdot 4)$ & $350(6 \cdot 1)$ \\
1989 & $90(12 \cdot 9)$ & $246(4 \cdot 8)$ & $336(5 \cdot 8)$ \\
1990 & $74(10 \cdot 7)$ & $179(3 \cdot 4)$ & $253(4 \cdot 2)$ \\
1991 & $63(9 \cdot 1)$ & $177(3 \cdot 3)$ & $240(4 \cdot 0)$ \\
1992 & $66(9 \cdot 1)$ & $148(2 \cdot 8)$ & $214(3 \cdot 6)$ \\
\hline
\end{tabular}

insignificant in contributing to the cause of death. A review of necropsy reporting of infant deaths registered in 1990 has resulted in a higher number of cases of SIDS being coded directly to 798.0 for 1990 and subsequent years. The classification of SIDS used in this report is by the number of cases captured by the SIDS Y indicator.

Similar information on postneonatal and total mortality from SIDS for 1991 and 1992 was obtained in collaboration with the Department of Health. Deaths are registered with the Department of Justice. The Department of Health subsequently receives notification of the official cause of death, which may be delayed if there is to be an inquest. Thus official mortality figures for recent years are not readily available. We established a network of paediatricians, pathologists, and coroners to establish the cause of death.

The total number of postneonatal deaths are final for these years, but some causes of death for 1992 are provisional as some coroners may, for example, certify a death as due to 'overlaying', whereas we have provisionally classified the death as due to SIDS. We have previously shown, however, that our diagnosis is rarely different from that of the coroner. The number of deaths from SIDS in 1992 may be slightly underestimated (probably by no more than three) as some deaths outside the postneonatal period may not have been identified.

Ethnic grouping is as Maori and non-Maori. Ethnicity is classified by the Department of Statistics using information recorded on the Department of Justice form Guide to person registering $a$ death and the crossmatched birth

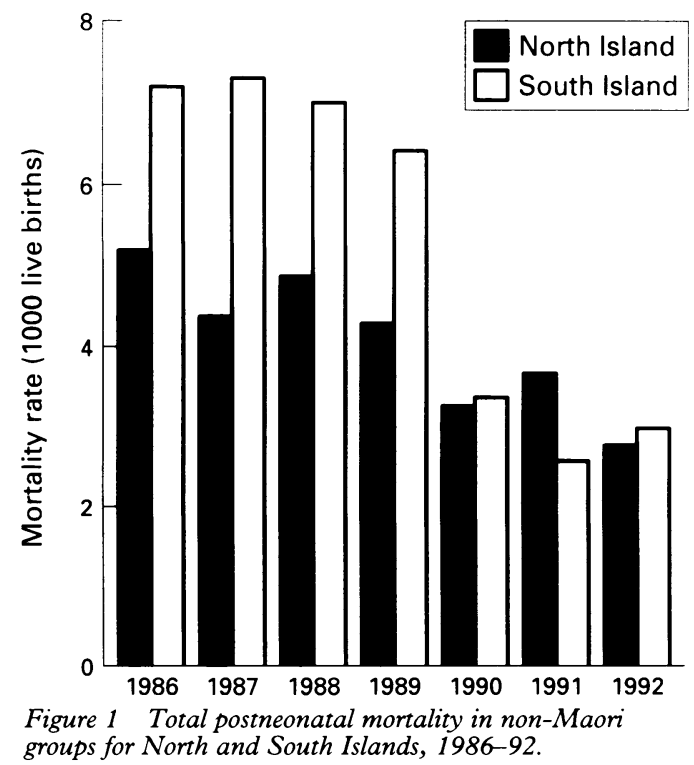

registration form. If the infant is reported to have $50 \%$ or more Maori blood then he or she is classified as Maori. Non-Maori infants are those not of $50 \%$ or more Maori ancestry and are predominantly of European origin. Infant death records are matched with the corresponding birth registration form to validate ethnic status.

The number of live births by ethnicity and region for years 1991 and 1992 was purchased from the Department of Statistics.

\section{Results}

POSTNEONATAL MORTALITY

Table 1 gives the total postneonatal mortality for the years 1986 to 1992 by ethnicity. Total mortality decreased dramatically in 1990 and has continued to decrease in 1991 and 1992. The decrease has been greater in non-Maori than in Maori groups.

To examine for changes in regional postneonatal mortality only non-Maori groups have been considered. As most Maori people live in North Island, ethnicity may confound regional mortality data. Figure 1 shows the postneonatal mortality for non-Maori infants for North and South Islands. In the first part of the study period mortality was higher in South Island than in North Island, but in the 1990s the mortality was similar. The largest decrease in postneonatal mortality has occurred in the South Island.

\section{MORTALITY FROM SIDS}

Table 2 shows the changes in mortality from SIDS by ethnicity. The greatest decrease occurred in non-Maori groups, whereas the decrease in Maori groups is more modest.

Figure 2 shows the number of deaths from SIDS by month of occurrence. In the 1980 s there was a marked winter peak (MayOctober). The reduction in SIDS in the 1990s occurred predominantly in the winter, with little, if any, change in the summer months. A winter peak still persists.

\section{Discussion}

There is a high degree of standardisation of classification of postneonatal deaths in New Zealand. Almost all sudden and unexpected deaths will be reported to the coroner, who will usually order a necropsy. In the nationwide three year SIDS case-control study $68 \%$ of all postneonatal deaths were classified as SIDS. Necropsies were carried out on $98 \%$ of the infants who died from SIDS. In addition, in 1987 we held a consensus meeting

Table 2 National total SIDS: numbers (rates per 1000 live births) by ethnicity, 1986-92

\begin{tabular}{llll}
\hline Year & Maori & Non-Maori & Total \\
\hline 1986 & $48(7 \cdot 4)$ & $165(3 \cdot 6)$ & $213(4 \cdot 0)$ \\
1987 & $57(8 \cdot 2)$ & $180(3 \cdot 7)$ & $237(4 \cdot 3)$ \\
1988 & $57(8 \cdot 4)$ & $197(3 \cdot 9)$ & $254(4 \cdot 4)$ \\
1989 & $69(9 \cdot 9)$ & $168(3 \cdot 3)$ & $237(4 \cdot 1)$ \\
1990 & $58(8 \cdot 3)$ & $117(2 \cdot 2)$ & $175(2 \cdot 9)$ \\
1991 & $48(6 \cdot 9)$ & $100(1 \cdot 9)$ & $148(2 \cdot 5)$ \\
1992 (provisional) & $50(6 \cdot 9)$ & $85(1 \cdot 6)$ & $135(2 \cdot 3)$ \\
\hline
\end{tabular}




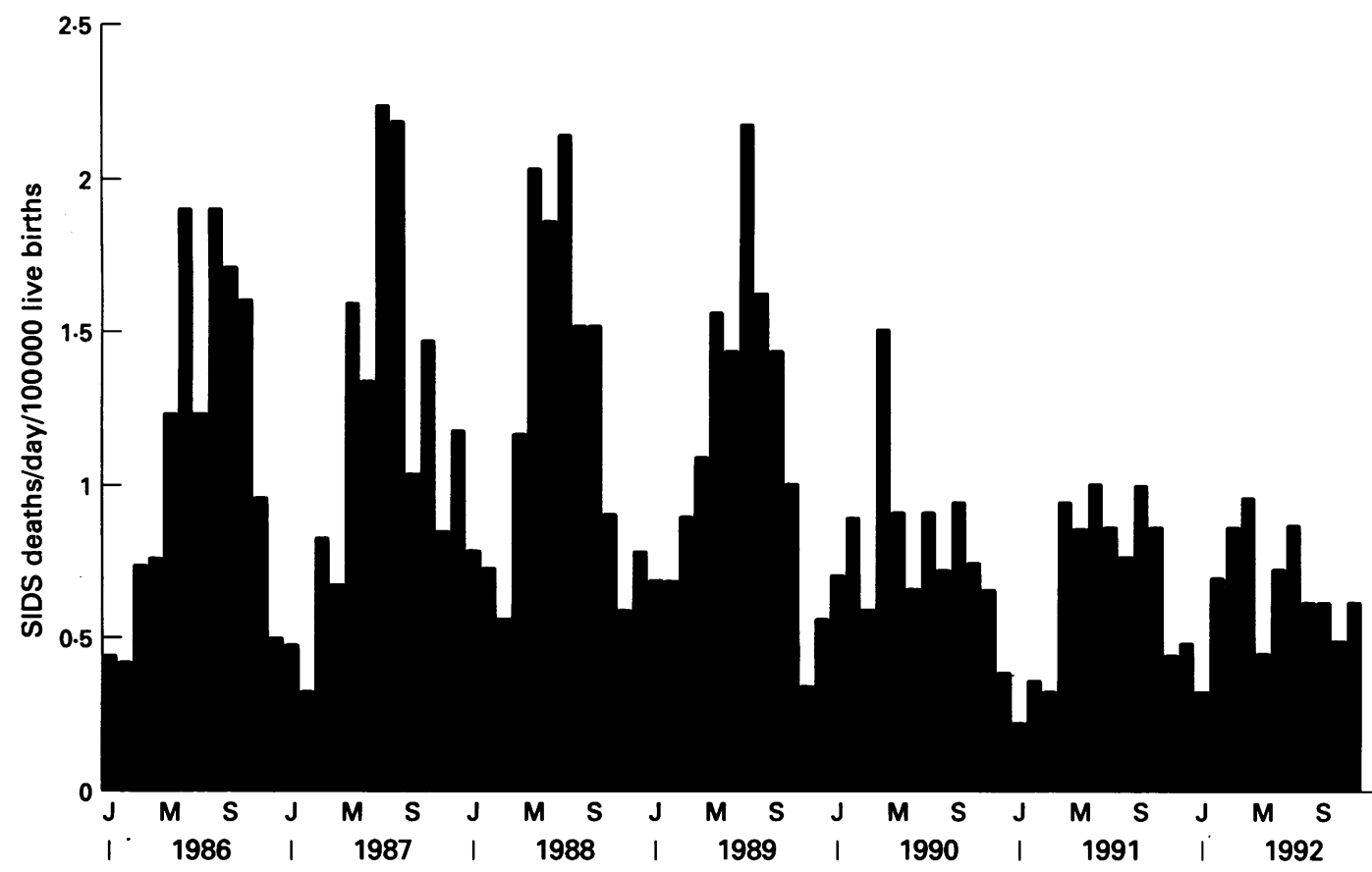

Figure 2 Number of deaths from SIDS each day per 100000 live births in year of death registration by month of occurrence ( $f=$ fanuary, $M=M a y, S=$ September).

of pathologists to establish uniformity of diagnosis for the SIDS case-control study. ${ }^{1}$

We have previously reported that mortality from SIDS decreased in New Zealand in 1990 and that this was associated with a decrease in the proportion of infants sleeping prone. ${ }^{9}$ In 1983 the proportion of infants sleeping prone in New Zealand was reported to be $46 \% .^{10}$ In the first year (1 November 1987-31 October 1988) of the SIDS nationwide case-control study the prevalence of the prone position was $43 \% .^{111}$ For the 12 months beginning in August 1990 the proportion of infants sleeping in the prone position decreased to $24 \% .^{11}$ From August 1991 the proportion decreased to less than $10 \%^{10}$ and a recent cross sectional survey indicates it is now less than $5 \% .^{12}$

The Cot Death Prevention Programme initially targeted three risk factors: prone sleeping position, smoking in pregnancy and around the infant in the first year of life, and bottle feeding. In 1992 a fourth message was added: 'do not sleep with your infant.' 7 Breast feeding rates in New Zealand are high compared with the United Kingdom ${ }^{13}$ and will be difficult to improve. Maternal smoking rates are difficult to change and have not changed over this time period. There is some evidence to suggest that the prevalence of bed sharing has decreased slightly. ${ }^{12}$ Advice on the thermal care of infants is part of the United Kingdom's 'Back to sleep' campaign, but is not part of the National Cot Death Prevention Programme in New Zealand. Changes in the amount of clothing and bedding covering the infants were not measured in the last two years of this study.

The decrease in mortality from SIDS has been dramatic. Change in the diagnostic classification of SIDS is unlikely to explain this change as there has been a corresponding decrease in postneonatal mortality. Furthermore, postmeonatal mortality has been constant at approximately $6 / 1000$ live births for over two decades and has suddenly decreased by over a third.

The fact that mortality from SIDS has not decreased as rapidly in Maori groups as in non-Maori groups has led to considerable debate in New Zealand. There are several issues. The first relates to the definition of ethnicity. Currently a biological definition of ethnicity is used in mortality data. Department of Health mortality data ethnicity classification is provided by the Department of Statistics, as detailed earlier. Legislative change is necessary to the Births, Deaths, and Marriages Registration Act before the implementation of revised format ethnicity questions can proceed. Births, deaths, and marriages registration legislation has been presented to Parliament and is currently before the Select Committee. A cultural definition of ethnicity may be more appropriate. We have found that almost as many mothers perceive themselves to be Maori who report having 25\% Maori blood as mothers who report having $100 \%$ Maori blood (unpublished observations). The relative risk of SIDS for Maori infants compared with nonMaori infants was approximately 2.4 in the late 1980s using the biological definition of ethnicity. In the case-control study, however, when a cultural definition of ethnicity was used (one or both parents reporting being Maori), the odds ratio was $3 \cdot 7 .{ }^{14}$ The increased risk appeared to be largely explained by higher prevalences of maternal smoking, bed sharing, and other known socioeconomic risk factors. ${ }^{14}$

Although we believe that the identified risk factors for SIDS are applicable to all ethnic groups the way prevention messages best reach the various ethnic groups may well be different. For non-Maori groups the written word has been successful. For Maori groups the message should be delivered orally by a culturally appropriate messenger. ${ }^{15}$ 
South Island has had a higher total postneonatal mortality and mortality from SIDS than North Island. With the change in the prevalence of the prone sleeping position the postneonatal mortality for non-Maori groups is now the same in the two islands. As most Maori groups live in North Island and they have a higher postneonatal mortality, the postneonatal mortality for the total population is now higher in North Island than in South Island.

It seems likely that the change in regional mortality is due to changes in the prone sleeping position, though changes in mortality due to changes in the thermal insulation of infants cannot be entirely excluded. In 1989 a centre in South Island recommended a reduction in thermal insulation of infants. ${ }^{16}$ This coincided with the change in the reduction in the prevalence of infants sleeping prone. We have been unable to show that the mean thermal insulation of infants changed during the three year case-control study. In addition, based on data from Avon, ${ }^{17}$ the proportion of deaths which could be attributed to excessive thermal insulation is small. ${ }^{18}$

Most epidemiological studies have found an increased risk of SIDS during the winter months. The reduction in mortality from SIDS in New Zealand has occurred predominantly in the winter months.

It has been suggested that the prone sleeping position may reduce the ability of the infant to lose heat from the face if exposed to heat stress. ${ }^{19}$ Furthermore, when infants sleep prone the risk of SIDS is increased by recent illness and the use of heating in bedrooms. ${ }^{20}$ The change in mortality from SIDS observed in this study leads to the suggestion that the mechanism of death associated with the prone sleeping position is related in some way to temperature. The decrease in mortality has been greatest in South Island, which is appreciably colder than North Island, especially at night, and during the winter months. Whether this is due to a direct effect of temperature or related to other factors, such as infant care practices in colder conditions, needs to be examined.

We thank the paediatricians, pathologists, and coroners who participated in the study, which allows us to report these recen changes in mortality. This is part of a joint project of the New Zealand Cot Death Study Group and the Royal New Zealand Plunket Society to monitor changes in mortality and the prevalence of risk factors for SIDS funded by the Cot Death Association (co-investigators: Ms A Counsell, Dr D Geddis, Ms N Taylor, Dr R Scragg, Mr A Stewart, Dr R Ford, and Dr B Taylor). Mrs Everard was funded by the Cot Death Association. We thank Mr J Thompson for help with database managent. We also thank the staff of the New Zealand management. We also thank the staff of the New Zealand Health Information Service for assistance in the production and
provision of infant mortality data. Mrs Brunt acknowledges provision of infant mortality data. Mrs Brunt acknowledges
permission to publish from the Director-General of Health. permission to publish from the Director-General of Health.
The opinions expressed in the paper do not necessarily reflect The opinions expressed in the paper do not necessarily reflect
the official views of the Ministry of Health. The Ministry of the official views of the Ministry of Health. The Ministry of
Health gives no indemnity as to the correctness of the information or data supplied. The Ministry of Health shall not be liable for any loss or damage arising directly or indirectly from the supply of this information.

1 Mitchell EA, Scragg R, Stewart AW, et al. Results from the first year of the New Zealand cot death study. $N Z$ Med $\mathscr{f}$ 1991; 104: 71-6.

2 Mitchell EA. Sleeping position of infants and the sudden infant death syndrome. Acta Paediatr Suppl 1993; 389: 387-9.

3 Haglund B, Cnattingius S. Cigarette smoking as a risk factor for sudden infant death syndrome: a population based for sudden infant death syndrome: a pop
study. Am f Public Health 1990; 80: 29-32.

4 Schoendorf KC, Kiely JL. Relationship of sudden infant death syndrome to maternal smoking during and after pregnancy. Pediatrics 1992; 90: 905-8.

5 Damus K, Pakter J, Krongrad E, Standfast SJ, Hoffman HJ Postnatal medical and epidemiological risk factors for the sudden infant death syndrome. In: Harper RM, Hoffman $\mathrm{H}$, eds. Sudden infant death syndrome: risk factors and basic mechanisms. New York: PMA, 1988; 187-201.

6 Engelberts AC, Jonge GA de. Choice of sleeping position for infants: possible association with cot death. Arch Dis for infants: possible as

7 Mitchell EA, Taylor BJ, Ford RPK, et al. Four modifiable and other major risk factors for cot death: the New Zealand Study. $\mathcal{F}$ Paediatr Child Health 1992; 28 (suppl 1): S3-8.

8 Mitchell EA, Aley P, Eastwood J. The National Cot Death Programme in New Zealand. Aust F Public Health 1992; 16: $1-58-61$.

9 Mitchell EA, Ford RPK, Taylor BJ, et al. Further evidence supporting a causal relationship between prone sleeping position and SIDS. F Pediatr Child Health 1992; 28 (suppl position and $\mathrm{S} 9-12$.

10 Hassall IB, Vandenberg M. Infant sleep position: a New Zealand survey. $N Z$ Med f 1985; 98: 97-9.

11 Mitchell EA, Tonkin S. Publicity, infants sleeping position and SIDS [letter]. BMF 1993; 306: 858.

2 Scragg LK, Mitchell EA, Tonkin SL, Hassall IB. Evaluation of the Cot Death Prevention Programme in South Auckland. N Z Med f 1993; 106: 8-10.

13 Emery JL, Scholey S, Taylor EM. Decline in breast feeding. Arch Dis Child 1990; 65: 369-72.

14 Mitchell EA, Stewart AW, Scragg R, et al. Ethnic differences in mortality rate from sudden infant death synences in mortality rate from sudden infant
drome in New Zealand. BMF 1993; 306: 13-6.

15 Stewart A, Mitchell EA, Tipene-Leach D, Fleming P. Lessons from the New Zealand and United Kingdom cot death campaigns. Acta Paediatr Suppl 1993; 389: 119-23

16 Taylor BJ. A review of epidemiological studies of sudden infant death syndrome in southern New Zealand. f Paediatr Child Health 1991; 27: 344-8.

17 Fleming PJ, Gilbert R, Azaz Y, et al. Interaction between bedding and sleeping position in sudden infant death syndrome: a population based case-control study. $B M \mathcal{J}$ 1990; 301: 85-9.

18 Mitchell EA. Cot death and overheating [letter]. $N Z$ Med $f$ 1991; 104: 148-9.

19 Nelson EAS, Taylor BJ, Weatherall L. Sleeping position and infant bedding may predispose to sudden infant death syndrome. Lancet 1989; i: 199-200.

20 Ponsonby A-L, Dwyer T, Gibbons LE, Cochrane JA, Wang Y-G. Factors potentiating the risk of sudden infant death syndrome associated with the prone position. $N$ Engl $\mathcal{f}$ Med 1993; 329: 377-82. 